\title{
Min And Max Triangular Extreme Interval Values And Statistics
}

Marsha Jance, Ph.D., Indiana University, USA

Nick Thomopoulos, Ph.D., Illinois Institute of Technology, USA

\begin{abstract}
This paper concerns the triangular distribution and shows how to find the min and max extreme interval values and related statistics (mean, standard deviation, mode, and median) for a range of observation sizes, $n$. The extreme interval value, denoted as $g_{\alpha}$, represents a bound where the probability of any value less than $g_{\alpha}$ is $\alpha$. Tables and an application are provided.
\end{abstract}

Keywords: Min and Max Triangular Values, Min and Max Triangular Extreme Values

\section{INTRODUCTION}

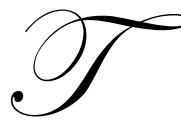

he min and max triangular extreme interval values and statistics: expected value, standard deviation, median, and mode are found for different observation sizes and probabilities $\alpha$. An extreme interval value $g_{\alpha}$ is a bound where a specific percentage of the data is less than $g_{\alpha}$. For example, given the probability $\mathrm{P}\left(\mathrm{g}<\mathrm{g}_{0.90}\right)=0.90$, the extreme interval value is $\mathrm{g}_{0.90}$ and $90 \%$ of the data is below $\mathrm{g}_{0.90}$. Jance's work Calculating Min and Max Extreme Interval Values for Various Distributions shows the min and max extreme interval values and statistics for different observation sizes for the normal, uniform, and exponential distributions.

In this paper an analysis of the min and max triangular extreme interval values and statistics is presented. In addition, it is shown how to find the min and max extreme interval values for different parameter values of $a, b$, and $\mathrm{c}$ provided that $\mathrm{a}<\mathrm{c}<\mathrm{b}$. Finally, an application and tables of some of the min and max extreme interval values and statistics for different observation sizes are provided.

\section{MIN AND MAX TRIANGULAR VALUES}

The minimum $(\min )$ and maximum $(\max )$ values in a sample of $\mathrm{n}$ observations are selected. The $\mathrm{n}$ observations come from a continuous distribution with probability density function $\mathrm{f}(\mathrm{x})$ and cumulative distribution function $\mathrm{F}(\mathrm{x})$. The min observation value has a probability density function of $\mathrm{h}(\mathrm{g})=\mathrm{nf}(\mathrm{g})(1-\mathrm{F}(\mathrm{g}))^{\mathrm{n}-1}$ and the max observation value has a probability density function of $\mathrm{h}(\mathrm{g})=\mathrm{nf}(\mathrm{g}) \mathrm{F}(\mathrm{g})^{\mathrm{n}-1}$ (Hines, Montgomery, Goldsman, and Borror 215).

Suppose that the $\mathrm{n}$ observations come from a triangular distribution with parameters $\mathrm{a}=0, \mathrm{~b}=1$, and $\mathrm{c}$ where $\mathrm{a}<\mathrm{c}<\mathrm{b}$. The following are the min and max triangular probability density functions, cumulative distribution functions, expected values, and standard deviations for an observation size of $\mathrm{n}$ and parameters $\mathrm{a}=0, \mathrm{~b}=1$, and $0<$ $\mathrm{c}<1$.

Min triangular probability density functions:

$$
\begin{gathered}
h(g)=n \frac{2 g}{c}\left(1-\frac{g^{2}}{c}\right)^{(n-1)} \text { when } 0 \leq \mathrm{g} \leq \mathrm{c} \\
\mathrm{h}(\mathrm{g})=\mathrm{n} \frac{2(1-\mathrm{g})}{(1-\mathrm{c})}\left(\frac{(1-\mathrm{g})^{2}}{(1-\mathrm{c})}\right)^{(\mathrm{n}-1)} \text { when } \mathrm{c}<\mathrm{g} \leq 1
\end{gathered}
$$


Min triangular cumulative distribution functions:

$$
\begin{gathered}
H(g)=\int_{0}^{g} n \frac{2 g}{c}\left(1-\frac{g^{2}}{c}\right)^{(n-1)} \text { dg when } 0 \leq \mathrm{g} \leq \mathrm{c} \\
\mathrm{H}(\mathrm{g})=\int_{0}^{\mathrm{c}} \mathrm{n} \frac{2 \mathrm{~g}}{\mathrm{c}}\left(1-\frac{\mathrm{g}^{2}}{\mathrm{c}}\right)^{(\mathrm{n}-1)} \mathrm{dg}+\int_{\mathrm{c}}^{\mathrm{g}} \mathrm{n} \frac{2(1-\mathrm{g})}{(1-\mathrm{c})}\left(\frac{(1-\mathrm{g})^{2}}{(1-\mathrm{c})}\right)^{(\mathrm{n}-1)} \text { dg when } \mathrm{c}<\mathrm{g} \leq 1
\end{gathered}
$$

Min triangular expected value:

$$
\mu=\int_{0}^{c} \operatorname{gn} \frac{2 g}{c}\left(1-\frac{g^{2}}{c}\right)^{(n-1)} d g+\int_{c}^{1} g n \frac{2(1-g)}{(1-c)}\left(\frac{(1-g)^{2}}{(1-c)}\right)^{(n-1)} d g
$$

Min triangular standard deviation:

$$
\begin{gathered}
E\left(g^{2}\right)=\int_{0}^{c} g^{2} n \frac{2 g}{c}\left(1-\frac{g^{2}}{c}\right)^{(n-1)} d g+\int_{c}^{1} g^{2} n \frac{2(1-g)}{(1-c)}\left(\frac{(1-g)^{2}}{(1-c)}\right)^{(n-1)} d g \\
\sigma=\sqrt{E\left(g^{2}\right)-\mu^{2}}
\end{gathered}
$$

Max triangular probability density functions:

$$
\begin{gathered}
h(g)=n \frac{2 g}{c}\left(\frac{g^{2}}{c}\right)^{(n-1)} \text { when } 0 \leq \mathrm{g} \leq \mathrm{c} \\
\mathrm{h}(\mathrm{g})=\mathrm{n} \frac{2(1-\mathrm{g})}{(1-\mathrm{c})}\left(1-\frac{(1-\mathrm{g})^{2}}{(1-\mathrm{c})}\right)^{(n-1)} \text { when } \mathrm{c}<\mathrm{g} \leq 1
\end{gathered}
$$

Max triangular cumulative distribution functions:

$$
\begin{gathered}
H(g)=\int_{0}^{g} n \frac{2 g}{c}\left(\frac{g^{2}}{c}\right)^{(n-1)} \text { dg when } 0 \leq \mathrm{g} \leq \mathrm{c} \\
\mathrm{H}(\mathrm{g})=\int_{0}^{\mathrm{c}} \mathrm{n} \frac{2 \mathrm{~g}}{\mathrm{c}}\left(\frac{\mathrm{g}^{2}}{\mathrm{c}}\right)^{(\mathrm{n}-1)} \mathrm{dg}+\int_{\mathrm{c}}^{\mathrm{g}} \mathrm{n} \frac{2(1-\mathrm{g})}{(1-\mathrm{c})}\left(1-\frac{(1-\mathrm{g})^{2}}{(1-\mathrm{c})}\right)^{(\mathrm{n}-1)} \mathrm{dg} \text { when } \mathrm{c}<\mathrm{g} \leq 1
\end{gathered}
$$

Max triangular expected value:

$$
\mu=\int_{0}^{c} g n \frac{2 g}{c}\left(\frac{g^{2}}{c}\right)^{(n-1)} d g+\int_{c}^{1} g n \frac{2(1-g)}{(1-c)}\left(1-\frac{(1-g)^{2}}{(1-c)}\right)^{(n-1)} d g
$$

Max triangular standard deviation:

$$
\begin{gathered}
E\left(g^{2}\right)=\int_{0}^{c} g^{2} n \frac{2 g}{c}\left(\frac{g^{2}}{c}\right)^{(n-1)} d g+\int_{c}^{1} g^{2} n \frac{2(1-g)}{(1-c)}\left(1-\frac{(1-g)^{2}}{(1-c)}\right)^{(n-1)} d g \\
\sigma=\sqrt{E\left(g^{2}\right)-\mu^{2}}
\end{gathered}
$$


A VBA application was written to find the min and max triangular extreme interval values and statistics for different observation sizes. The program first evaluates the min and max cumulative distribution function values for $\mathrm{g}$ values ranging from $\mathrm{g}=0$ to $\mathrm{g}=1$ in increments of 0.0001 . Then interpolation is used to find the min and max triangular extreme interval values for a specific probability $\alpha$. The program looks for the largest cumulative distribution function value $\mathrm{H}\left(\mathrm{g}_{1}\right)$ below $\alpha$ and the smallest cumulative distribution function value $\mathrm{H}\left(\mathrm{g}_{2}\right)$ above $\alpha$. The extreme interval value $\mathrm{g}_{\alpha}$ is found using the interpolation formula:

$\mathrm{g}_{\alpha}=\mathrm{g}_{1}+\left(\mathrm{g}_{2}-\mathrm{g}_{1}\right) \frac{\alpha-\mathrm{H}\left(\mathrm{g}_{1}\right)}{\mathrm{H}\left(\mathrm{g}_{2}\right)-\mathrm{H}\left(\mathrm{g}_{1}\right)}$ where $\mathrm{g}_{1}<\mathrm{g}_{\alpha}<\mathrm{g}_{2}$ and $\mathrm{H}\left(\mathrm{g}_{1}\right)<\alpha<H\left(\mathrm{~g}_{2}\right) \quad$ (Law $\quad$ and $\quad$ Kelton 470$)$. MATLAB's Excel Link is used in conjunction with VBA to find the min and max expected values and standard deviations.

\section{ANALYSIS}

Tables 1 through 6 display some of the min and max triangular extreme interval values and statistics for different observation sizes and parameters $\mathrm{a}=0, \mathrm{~b}=1$, and $\mathrm{c}=0.10,0.50$, and 0.90 . For example, in Table 1 the min extreme interval value is $\mathrm{g}_{0.05}=0.02262$ when $\mathrm{n}=10, \alpha=0.05$, and $\mathrm{c}=0.10$. In Table 4 the max extreme interval value is $\mathrm{g}_{0.05}=0.51732$ when $\mathrm{n}=10, \alpha=0.05$, and $\mathrm{c}=0.10$.

In Tables 1, 2, and 3 one can see that the min extreme interval values and expected values are decreasing as the observation size increases. In Tables 4, 5, and 6 one can see that the max extreme interval values and expected values are increasing as the observation size increases.

In Table 1 the mode is 0.10 for $n=1$ to $n=5$ and then decreases as $n$ increases. In Table 6 the mode is 0.90 for $\mathrm{n}=1$ to $\mathrm{n}=5$ and then increases as $\mathrm{n}$ increases. The mode decreases in Tables 2 and 3 and increases in Tables 4 and 5 as $n$ gets larger. In the tables the $\min$ and max values are the same when $n=1$. Note, the extreme interval value $\mathrm{g}_{0.50}$ is also the median.

In the tables the min and max standard deviations are decreasing as the observation size increases. Also, the min and max standard deviation values are the same in Tables 1 and 6, 2 and 5, and 3 and 4.

\section{OTHER PARAMETER VALUES}

A triangular variable with parameters $\mathrm{a}, \mathrm{b}$, and $\mathrm{c}(\mathrm{a}<\mathrm{c}<\mathrm{b})$ can be generated by using the following formula: $\mathrm{a}+(\mathrm{b}-\mathrm{a}) \mathrm{x}$ where $\mathrm{x}$ follows a triangular distribution with parameters $\mathrm{a}=0, \mathrm{~b}=1$, and $\frac{(\mathrm{c}-\mathrm{a})}{(\mathrm{b}-\mathrm{a})}$ (Law and Kelton 469). This information will be used to find the min and max triangular extreme interval values for different parameter values of $\mathrm{a}, \mathrm{b}$, and $\mathrm{c}$ provided that $\mathrm{a}<\mathrm{c}<\mathrm{b}$.

First, the min and max extreme interval values $\left(g_{\alpha}\right)$ are determined for $n, \alpha, a=0, b=1$, and $\frac{(c-a)}{(b-a)}$. Then the equation $\mathrm{g}_{\alpha}^{\prime}=\mathrm{a}+(\mathrm{b}-\mathrm{a}) \mathrm{g}_{\alpha}$ is used to find the min and max extreme interval values for $\mathrm{n}, \alpha, \mathrm{a}, \mathrm{b}$, and $\mathrm{c}$ where a $<\mathrm{c}<\mathrm{b}$. The following example finds the min and max extreme interval values for $\mathrm{n}=15, \alpha=0.95, \mathrm{a}=11, \mathrm{~b}=21$, and $\mathrm{c}=20$.

In Table 3 the min extreme interval value when $\mathrm{n}=15, \alpha=0.95, \mathrm{a}=0, \mathrm{~b}=1$, and $\mathrm{c}=\frac{(20-11)}{(21-11)}=0.90$ is $\mathrm{g}_{0.95}=0.40365$. Thus, the min extreme interval value when $\mathrm{n}=15, \alpha=0.95, \mathrm{a}=11, \mathrm{~b}=21$, and $\mathrm{c}=20$ is $\mathrm{g}_{0.95}^{\prime}=$ $\mathrm{a}+(\mathrm{b}-\mathrm{a}) \mathrm{g}_{0.95}=11+(21-11) \times 0.40365=15.03650$. Here is the proof that $\mathrm{g}_{0.95}^{\prime}=15.03650$ is the min extreme interval value:

$$
\mathrm{H}\left(\mathrm{g}^{\prime}\right)=\int_{11}^{15.03650} 15 \times \frac{2\left(\mathrm{~g}^{\prime}-11\right)}{(21-11)(20-11)}\left(1-\frac{\left(\mathrm{g}^{\prime}-11\right)^{2}}{(21-11)(20-11)}\right)^{14} \mathrm{dg}^{\prime} \approx 0.95
$$


In Table 6 the max extreme interval value when $\mathrm{n}=15, \alpha=0.95, \mathrm{a}=0, \mathrm{~b}=1$, and $\mathrm{c}=\frac{(20-11)}{(21-11)}=0.90$ is $\mathrm{g}_{0.95}=0.98152$. Thus, the max extreme interval value when $\mathrm{n}=15, \alpha=0.95, \mathrm{a}=11, \mathrm{~b}=21$, and $\mathrm{c}=20$ is $\mathrm{g}_{0.95}^{\prime}=\mathrm{a}+(\mathrm{b}-\mathrm{a}) \mathrm{g}_{0.95}=11+(21-11) \times 0.98152=20.81520$. Here is the proof that $\mathrm{g}_{0.95}^{\prime}=20.81520$ is the max extreme interval value:

$$
\begin{aligned}
H\left(g^{\prime}\right)= & \int_{11}^{20} 15 \times \\
& \frac{2\left(g^{\prime}-11\right)}{(21-11)(20-11)}\left(\frac{\left(g^{\prime}-11\right)^{2}}{(21-11)(20-11)}\right)^{14} \mathrm{dg}^{\prime} \\
& +\int_{20}^{20.81520} 15 \times \frac{2\left(21-\mathrm{g}^{\prime}\right)}{(21-11)(21-20)}\left(1-\frac{\left(21-\mathrm{g}^{\prime}\right)^{2}}{(21-11)(21-20)}\right)^{14} \mathrm{dg}^{\prime} \approx 0.95
\end{aligned}
$$

\section{APPLICATION}

A major project will commence once all four independent subprojects are completed. Estimates on the time to completion of each subproject are the following: the minimum time is 35 days, the maximum time is 47 days, and the most likely time is 45.8 days. Four teams are working on the subprojects ( 1 team per subproject). The chair of the major project wants to know the average time for the completion of the four subprojects. In addition, the chair wants to know the time with $95 \%$ probability that the major project can begin.

Let $g^{\prime}=\max \left(t_{1}, t_{2}, t_{3}, t_{4}\right)$ where $g^{\prime}$ is the time when the major project can commence and $t_{i}$ is the completion time of subproject $\mathrm{i}$. The max is needed since the major project cannot begin until the slowest of the subprojects is finished. Assume that $t_{i}$ follows a triangular distribution with parameters $a=35, b=47$, and $c=$ 45.8 .

In Table 6 the max expected value when $\mathrm{n}=4, \mathrm{a}=0, \mathrm{~b}=1$, and $\mathrm{c}=\frac{(45.8-35)}{(47-35)}=0.90$ is $\mu=0.84658$. Then $\mu^{\prime}=\mathrm{a}+(\mathrm{b}-\mathrm{a}) \mu=35+(47-35) \times 0.84658=45.15896$ when $\mathrm{n}=4, \mathrm{a}=35, \mathrm{~b}=47$, and $\mathrm{c}=45.8$. Thus, the average time is 45.2 days before the major project can commence.

In Table 6 the max extreme interval value when $\mathrm{n}=4, \alpha=0.95, \mathrm{a}=0, \mathrm{~b}=1$, and $\mathrm{c}=\frac{(45.8-35)}{(47-35)}=0.90$ is $\mathrm{g}_{0.95}=0.96430$. Then $\mathrm{g}_{0.95}^{\prime}=\mathrm{a}+(\mathrm{b}-\mathrm{a}) \mathrm{g}_{0.95}=35+(47-35) \times 0.96430=46.57160$ when $\mathrm{n}=4, \alpha=0.95$, $\mathrm{a}=35, \mathrm{~b}=47$, and $\mathrm{c}=45.8$. Thus, there is a $95 \%$ probability that the major project will begin in 46.6 days.

\section{CONCLUSIONS}

The min and max triangular extreme interval values and statistics are discussed. Tables displaying some of the min and max triangular values for different observation sizes and values of $\mathrm{c}$ are provided. It is shown how to find the min and max extreme interval values for different parameter values of a, b, and c. Finally, an application is presented.

\section{AUTHOR INFORMATION}

Marsha Jance received her Ph.D. in Management Science from Illinois Institute of Technology Stuart School of Business in Chicago, Illinois. She is an Assistant Professor of Business Administration at Indiana University East in Richmond, Indiana.

Nick T. Thomopoulos is a professor at the Stuart School of Business, Illinois Institute of Technology. Nick has degrees in Business, Mathematics, and Industrial Engineering. He is the author of three books: Assembly Line Systems, Hayden Books, 1973, Applied Forecasting Methods, Prentice Hall, 1980 and Strategic Inventory Management and Planning, Hitchcock Publishing Co., 1990. 


\section{REFERENCES}

1. Hines, William W., Douglas C. Montgomery, David M. Goldsman, and Connie M. Borror. Probability and Statistics in Engineering Fourth Edition. John Wiley \& Sons, Inc., 2003.

2. Jance, Marsha L. Calculating Min and Max Extreme Interval Values for Various Distributions. Doctoral dissertation. Chicago, IL: Illinois Institute of Technology Stuart School of Business, 2007.

3. Law, Averill M., and W. David Kelton. Simulation Modeling and Analysis Third Edition. McGraw-Hill, 2000.

4. MATLAB: Version 7.8.0.347, The MathWorks, 2009.

5. Microsoft Excel: Professional Edition 2007, Redmond, WA: Microsoft Corporation, 2006. 


\begin{tabular}{|c|c|c|c|c|c|c|c|c|c|c|c|c|}
\hline $\bar{n}$ & $\bar{~} 0.01$ & 0.05 & 0.10 & 0.25 & (0.50 & 0.75 & 0.90 & 0.95 & 0.99 & $\overline{\mu \mu}$ & $\overline{\bar{\sigma} \sigma}$ & "MODE \\
\hline 1 & 0.03162 & 0.07071 & 0.10000 & 0.17842 & 0.32918 & 0.52566 & 0.70000 & 0.78787 & 0.90513 & 0.36667 & 0.22485 & 0.10000 \\
\hline 2 & 0.02239 & 0.05032 & 0.07164 & 0.11715 & 0.20226 & 0.32918 & 0.46652 & 0.55140 & 0.70000 & 0.23933 & 0.15701 & 0.10000 \\
\hline 3 & 0.01829 & 0.04117 & 0.05875 & 0.09562 & 0.15482 & 0.24703 & 0.35367 & 0.42419 & 0.55966 & 0.18431 & 0.12025 & 0.10000 \\
\hline 4 & 0.01584 & 0.03570 & 0.05099 & 0.08330 & 0.13005 & 0.20226 & 0.28859 & 0.34763 & 0.46652 & 0.15342 & 0.09790 & 0.10000 \\
\hline 5 & 0.01417 & 0.03195 & 0.04566 & 0.07477 & 0.11485 & 0.17412 & 0.24643 & 0.29690 & 0.40142 & 0.13351 & 0.08303 & 0.10000 \\
\hline 10 & 0.01002 & 0.02262 & 0.03237 & 0.05325 & 0.08183 & 0.11485 & 0.15449 & 0.18329 & 0.24643 & 0.08911 & 0.05009 & 0.07250 \\
\hline 15 & 0.00818 & 0.01848 & 0.02646 & 0.04358 & 0.06720 & 0.09396 & 0.12141 & 0.14147 & 0.18632 & 0.07176 & 0.03840 & 0.05870 \\
\hline 25 & 0.00634 & 0.01432 & 0.02051 & 0.03383 & 0.05229 & 0.07345 & 0.09380 & 0.10649 & 0.13479 & 0.05540 & 0.02874 & 0.04520 \\
\hline 50 & 0.00448 & 0.01013 & 0.01451 & 0.02395 & 0.03710 & 0.05229 & 0.06709 & 0.07626 & 0.09380 & 0.03934 & 0.02034 & 0.03180 \\
\hline 75 & 0.00366 & 0.00827 & 0.01185 & 0.01957 & 0.03033 & 0.04280 & 0.05499 & 0.06257 & 0.07717 & 0.03220 & 0.01670 & 0.02590 \\
\hline 100 & 0.00317 & 0.00716 & 0.01026 & 0.01695 & 0.02628 & 0.03710 & 0.04771 & 0.05433 & 0.06709 & 0.02792 & 0.01451 & 0.02240 \\
\hline
\end{tabular}

Table 2: Min Extreme Interval Values and Statistics $(a=0, b=1$, and $c=0.50)$

\begin{tabular}{|c|c|c|c|c|c|c|c|c|c|c|c|c|}
\hline $\mathbf{n}$ & 0.01 & 0.05 & 0.10 & 0.25 & 0.50 & 0.75 & 0.90 & 0.95 & 0.99 & $\mu$ & $\sigma$ & MODE \\
\hline 1 & 0.07071 & 0.15811 & 0.22361 & 0.35355 & 0.50000 & 0.64645 & 0.77639 & 0.84189 & 0.92929 & 0.50000 & 0.20412 & 0.50000 \\
\hline 2 & 0.05006 & 0.11252 & 0.16018 & 0.25882 & 0.38268 & 0.50000 & 0.60236 & 0.66563 & 0.77639 & 0.38333 & 0.16750 & 0.40820 \\
\hline 3 & 0.04089 & 0.09207 & 0.13136 & 0.21382 & 0.32117 & 0.43014 & 0.51825 & 0.57081 & 0.67179 & 0.32500 & 0.14699 & 0.31620 \\
\hline 4 & 0.03542 & 0.07982 & 0.11401 & 0.18627 & 0.28205 & 0.38268 & 0.46779 & 0.51375 & 0.60236 & 0.28790 & 0.13345 & 0.26730 \\
\hline 5 & 0.03169 & 0.07144 & 0.10211 & 0.16720 & 0.25441 & 0.34795 & 0.42956 & 0.47472 & 0.55385 & 0.26141 & 0.12343 & 0.23570 \\
\hline 10 & 0.02241 & 0.05058 & 0.07239 & 0.11908 & 0.18298 & 0.25441 & 0.32068 & 0.35977 & 0.42956 & 0.19110 & 0.09453 & 0.16220 \\
\hline 15 & 0.01830 & 0.04131 & 0.05916 & 0.09746 & 0.15026 & 0.21009 & 0.26674 & 0.30086 & 0.36356 & 0.15789 & 0.07950 & 0.13130 \\
\hline 25 & 0.01418 & 0.03201 & 0.04586 & 0.07564 & 0.11693 & 0.16423 & 0.20975 & 0.23762 & 0.29003 & 0.12349 & 0.06310 & 0.10100 \\
\hline 50 & 0.01002 & 0.02264 & 0.03244 & 0.05356 & 0.08297 & 0.11693 & 0.15001 & 0.17052 & 0.20975 & 0.08796 & 0.04545 & 0.07110 \\
\hline 75 & 0.00819 & 0.01849 & 0.02649 & 0.04375 & 0.06782 & 0.09569 & 0.12295 & 0.13992 & 0.17256 & 0.07200 & 0.03735 & 0.05790 \\
\hline 100 & 0.00709 & 0.01601 & 0.02295 & 0.03790 & 0.05877 & 0.08297 & 0.10668 & 0.12148 & 0.15001 & 0.06243 & 0.03245 & 0.05010 \\
\hline
\end{tabular}


Table 3: Min Extreme Interval Values and Statistics $(\mathrm{a}=\mathbf{0}, \mathrm{b}=1$, and $\mathrm{c}=0.90)$

\begin{tabular}{|c|c|c|c|c|c|c|c|c|c|c|c|c|}
\hline $\mathbf{n}$ & 0.01 & 0.05 & 0.10 & 0.25 & 0.50 & 0.75 & 0.90 & 0.95 & 0.99 & $\mu$ & $\sigma$ & MODE \\
\hline 1 & 0.09487 & 0.21213 & 0.30000 & 0.47434 & 0.67082 & 0.82158 & 0.90000 & 0.92929 & 0.96838 & 0.63333 & 0.22485 & 0.90000 \\
\hline 2 & 0.06717 & 0.15096 & 0.21491 & 0.34724 & 0.51342 & 0.67082 & 0.78447 & 0.83592 & 0.90000 & 0.50600 & 0.20983 & 0.54770 \\
\hline 3 & 0.05486 & 0.12352 & 0.17624 & 0.28687 & 0.43089 & 0.57709 & 0.69445 & 0.75395 & 0.84030 & 0.43369 & 0.19215 & 0.42430 \\
\hline 4 & 0.04752 & 0.10709 & 0.15296 & 0.24991 & 0.37841 & 0.51342 & 0.62761 & 0.68878 & 0.78447 & 0.38550 & 0.17718 & 0.35860 \\
\hline 5 & 0.04251 & 0.09584 & 0.13699 & 0.22432 & 0.34133 & 0.46683 & 0.57631 & 0.63690 & 0.73601 & 0.35045 & 0.16487 & 0.31620 \\
\hline 10 & 0.03007 & 0.06786 & 0.09712 & 0.15976 & 0.24550 & 0.34133 & 0.43024 & 0.48268 & 0.57631 & 0.25639 & 0.12681 & 0.21760 \\
\hline 15 & 0.02455 & 0.05543 & 0.07937 & 0.13075 & 0.20160 & 0.28187 & 0.35787 & 0.40365 & 0.48777 & 0.21184 & 0.10666 & 0.17620 \\
\hline 25 & 0.01902 & 0.04295 & 0.06152 & 0.10148 & 0.15688 & 0.22034 & 0.28141 & 0.31880 & 0.38912 & 0.16568 & 0.08465 & 0.13550 \\
\hline 50 & 0.01345 & 0.03038 & 0.04353 & 0.07186 & 0.11131 & 0.15688 & 0.20126 & 0.22878 & 0.28141 & 0.11802 & 0.06098 & 0.09530 \\
\hline 75 & 0.01098 & 0.02481 & 0.03554 & 0.05870 & 0.09099 & 0.12839 & 0.16496 & 0.18772 & 0.23152 & 0.09660 & 0.05011 & 0.07770 \\
\hline 100 & 0.00951 & 0.02148 & 0.03079 & 0.05085 & 0.07885 & 0.11131 & 0.14313 & 0.16298 & 0.20126 & 0.08376 & 0.04353 & 0.06730 \\
\hline
\end{tabular}

Table 4: Max Extreme Interval Values and Statistics $(a=0, b=1$, and $c=0.10)$

\begin{tabular}{|c|c|c|c|c|c|c|c|c|c|c|c|c|}
\hline $\mathbf{n}$ & 0.01 & 0.05 & 0.10 & 0.25 & 0.50 & 0.75 & 0.90 & 0.95 & 0.99 & $\mu$ & $\sigma$ & MODE \\
\hline 1 & 0.03162 & 0.07071 & 0.10000 & 0.17842 & 0.32918 & 0.52566 & 0.70000 & 0.78787 & 0.90513 & 0.36667 & 0.22485 & 0.10000 \\
\hline 2 & 0.10000 & 0.16408 & 0.21553 & 0.32918 & 0.48658 & 0.65276 & 0.78509 & 0.84904 & 0.93283 & 0.49400 & 0.20983 & 0.45230 \\
\hline 3 & 0.15970 & 0.24605 & 0.30555 & 0.42291 & 0.56911 & 0.71313 & 0.82376 & 0.87648 & 0.94514 & 0.56631 & 0.19215 & 0.57570 \\
\hline 4 & 0.21553 & 0.31122 & 0.37239 & 0.48658 & 0.62159 & 0.75009 & 0.84704 & 0.89291 & 0.95248 & 0.61450 & 0.17718 & 0.64140 \\
\hline 5 & 0.26399 & 0.36310 & 0.42369 & 0.53317 & 0.65867 & 0.77568 & 0.86301 & 0.90416 & 0.95749 & 0.64955 & 0.16487 & 0.68380 \\
\hline 10 & 0.42369 & 0.51732 & 0.56976 & 0.65867 & 0.75450 & 0.84024 & 0.90288 & 0.93214 & 0.96993 & 0.74361 & 0.12681 & 0.78240 \\
\hline 15 & 0.51223 & 0.59635 & 0.64213 & 0.71813 & 0.79840 & 0.86925 & 0.92063 & 0.94457 & 0.97545 & 0.78816 & 0.10666 & 0.82380 \\
\hline 25 & 0.61088 & 0.68120 & 0.71859 & 0.77966 & 0.84312 & 0.89852 & 0.93848 & 0.95705 & 0.98098 & 0.83432 & 0.08465 & 0.86450 \\
\hline 50 & 0.71859 & 0.77122 & 0.79874 & 0.84312 & 0.88869 & 0.92814 & 0.95647 & 0.96962 & 0.98655 & 0.88198 & 0.06098 & 0.90470 \\
\hline 75 & 0.76848 & 0.81228 & 0.83504 & 0.87161 & 0.90901 & 0.94130 & 0.96446 & 0.97519 & 0.98902 & 0.90340 & 0.05011 & 0.92230 \\
\hline 100 & 0.79874 & 0.83702 & 0.85687 & 0.88869 & 0.92115 & 0.94915 & 0.96921 & 0.97852 & 0.99049 & 0.91624 & 0.04353 & 0.93270 \\
\hline
\end{tabular}


Table 5: Max Extreme Interval Values and Statistics $(\mathrm{a}=\mathbf{0}, \mathrm{b}=1$, and $\mathrm{c}=\mathbf{0 . 5 0})$

\begin{tabular}{|c|c|c|c|c|c|c|c|c|c|c|c|c|}
\hline $\mathbf{n}$ & 0.01 & 0.05 & 0.10 & 0.25 & 0.50 & 0.75 & 0.90 & 0.95 & 0.99 & $\mu$ & $\boldsymbol{\sigma}$ & MODE \\
\hline 1 & 0.07071 & 0.15811 & 0.22361 & 0.35355 & 0.50000 & 0.64645 & 0.77639 & 0.84189 & 0.92929 & 0.50000 & 0.20412 & 0.50000 \\
\hline 2 & 0.22361 & 0.33437 & 0.39764 & 0.50000 & 0.61732 & 0.74118 & 0.83982 & 0.88748 & 0.94994 & 0.61667 & 0.16750 & 0.59180 \\
\hline 3 & 0.32821 & 0.42919 & 0.48175 & 0.56986 & 0.67883 & 0.78618 & 0.86864 & 0.90793 & 0.95911 & 0.67500 & 0.14699 & 0.68380 \\
\hline 4 & 0.39764 & 0.48625 & 0.53221 & 0.61732 & 0.71795 & 0.81373 & 0.88599 & 0.92018 & 0.96458 & 0.71210 & 0.13345 & 0.73270 \\
\hline 5 & 0.44615 & 0.52528 & 0.57044 & 0.65205 & 0.74559 & 0.83280 & 0.89789 & 0.92856 & 0.96831 & 0.73859 & 0.12343 & 0.76430 \\
\hline 10 & 0.57044 & 0.64023 & 0.67932 & 0.74559 & 0.81702 & 0.88092 & 0.92761 & 0.94942 & 0.97759 & 0.80890 & 0.09453 & 0.83780 \\
\hline 15 & 0.63644 & 0.69914 & 0.73326 & 0.78991 & 0.84974 & 0.90254 & 0.94084 & 0.95869 & 0.98170 & 0.84211 & 0.07950 & 0.86870 \\
\hline 25 & 0.70997 & 0.76238 & 0.79025 & 0.83577 & 0.88307 & 0.92436 & 0.95414 & 0.96799 & 0.98582 & 0.87651 & 0.06310 & 0.89900 \\
\hline 50 & 0.79025 & 0.82948 & 0.84999 & 0.88307 & 0.91703 & 0.94644 & 0.96756 & 0.97736 & 0.98998 & 0.91204 & 0.04545 & 0.92890 \\
\hline 75 & 0.82744 & 0.86008 & 0.87705 & 0.90431 & 0.93218 & 0.95625 & 0.97351 & 0.98151 & 0.99181 & 0.92800 & 0.03735 & 0.94210 \\
\hline 100 & 0.84999 & 0.87852 & 0.89332 & 0.91703 & 0.94123 & 0.96210 & 0.97705 & 0.98399 & 0.99291 & 0.93757 & 0.03245 & 0.94990 \\
\hline
\end{tabular}

Table 6: Max Extreme Interval Values and Statistics $(a=0, b=1$, and $c=0.90)$

\begin{tabular}{|c|c|c|c|c|c|c|c|c|c|c|c|c|}
\hline $\mathbf{n}$ & 0.01 & 0.05 & 0.10 & 0.25 & 0.50 & 0.75 & 0.90 & 0.95 & 0.99 & $\mu$ & $\sigma$ & MODE \\
\hline 1 & 0.09487 & 0.21213 & 0.30000 & 0.47434 & 0.67082 & 0.82158 & 0.90000 & 0.92929 & 0.96838 & 0.63333 & 0.22485 & 0.90000 \\
\hline 2 & 0.30000 & 0.44860 & 0.53348 & 0.67082 & 0.79774 & 0.88285 & 0.92836 & 0.94968 & 0.97761 & 0.76067 & 0.15701 & 0.90000 \\
\hline 3 & 0.44034 & 0.57581 & 0.64633 & 0.75297 & 0.84518 & 0.90438 & 0.94125 & 0.95883 & 0.98171 & 0.81569 & 0.12025 & 0.90000 \\
\hline 4 & 0.53348 & 0.65237 & 0.71141 & 0.79774 & 0.86995 & 0.91670 & 0.94901 & 0.96430 & 0.98416 & 0.84658 & 0.09790 & 0.90000 \\
\hline 5 & 0.59858 & 0.70310 & 0.75357 & 0.82588 & 0.88515 & 0.92523 & 0.95434 & 0.96805 & 0.98583 & 0.86649 & 0.08303 & 0.90000 \\
\hline 10 & 0.75357 & 0.81671 & 0.84551 & 0.88515 & 0.91817 & 0.94675 & 0.96763 & 0.97738 & 0.98998 & 0.91089 & 0.05009 & 0.92750 \\
\hline 15 & 0.81368 & 0.85853 & 0.87859 & 0.90604 & 0.93280 & 0.95642 & 0.97354 & 0.98152 & 0.99182 & 0.92824 & 0.03840 & 0.94130 \\
\hline 25 & 0.86521 & 0.89351 & 0.90620 & 0.92655 & 0.94771 & 0.96617 & 0.97949 & 0.98568 & 0.99366 & 0.94460 & 0.02874 & 0.95480 \\
\hline 50 & 0.90620 & 0.92374 & 0.93291 & 0.94771 & 0.96290 & 0.97605 & 0.98549 & 0.98987 & 0.99552 & 0.96066 & 0.02034 & 0.96820 \\
\hline 75 & 0.92283 & 0.93743 & 0.94501 & 0.95720 & 0.96967 & 0.98043 & 0.98815 & 0.99173 & 0.99634 & 0.96780 & 0.01670 & 0.97410 \\
\hline 100 & 0.93291 & 0.94567 & 0.95229 & 0.96290 & 0.97372 & 0.98305 & 0.98974 & 0.99284 & 0.99683 & 0.97208 & 0.01451 & 0.97760 \\
\hline
\end{tabular}

